patients admitted to six European hospitals", Eur. J. Clin. Pharmacol., 67, 1175- 1188.

5. Gallagher $P$, Lang $P$, Cherubini $A$ et al. (2011), "Prevalence of potentially inappropriate prescribing in an acutely ill population of older patients admitted to six European hospitals", Eur. J. Clin. Pharmacol., 67, 1175-1188.

6. Hartholt KA, van Beeck EF, Polinder S, van der Velde N, van Lieshout EM, Panneman MJ, van der Cammen TJ, Patka $\mathbf{P}$, Societal consequences of falls in the older population: injuries, healthcare costs, and long-term reduced quality of life. J Trauma. 2011 Sep; 71(3):748-53.)

7. Janice B. Schwartz, M.D., FACC, MAGS, FAHA (2015), Primary Prevention: Do the very elderly require a different approach?, Trends Cardiovasc Med. 2015 Apr; 25(3): 228-239.

8. O'Mahony D, O'Sullivan D, Byrne S, O'Connor MN, Ryan C, Gallagher P. (2015), "STOPP/START criteria for potentially inappropriate prescribing in older people: version 2", Age Ageing. 44(2), 213-218.

\title{
ĐẶC ĐIỂM LÂM SÀNG VÀ XQUANG CỦA BỂNH NHÂN THAY LẠI KHỚP HÁNG NHÂN TẠOO
}

\section{TÓM TẮT}

Phẫu thuât thay khớp háng ngày càng được thực hiện phổ biến để điều trị các bệnh lý gây tổn thươñ khớp háng. Tuy nhiên có một số trường hợp phẫu thuật thất bại và cần phải thay lại khớp háng nhân tạo. Mục tiêu: Đánh giá đặc điểm lâm sàng và Xquang của bệnh nhân thay lại khớp háng nhân tạo. Đối tượng và phương pháp: Nghiên cứu mô tả cắt ngang trên 50 bệnh nhân bị hỏng khớp háng nhân tạo không do nhiễm trùng và có chi định thay lại khớp háng. Kết quả: Có 41 bệnh nhân đã thay khớp háng toàn phần $(82 \%)$ và 9 bệnh nhân đã thay khớp háng bán phần $(18 \%)(p<0,001)$. Thời gian trung bình giữa 2 lần thay khớp là $75,8 \pm 68,1$ tháng. Thời gian giữa hai lần thay khớp của nhóm khớp có xi măng và không xi măng lần lượt là $121,0 \pm 68,6$ và $37,3 \pm 37,6$ tháng $(p<0,001)$. Nguyên nhân gây thất bai sau phấu thuật thay khớp háng hay gặp lần lượt là lỏng khớp $(72 \%)$, trât khớp (20\%), gãy xương quanh chuôi $(4 \%)$ và gãy chuôi $(4 \%)$. Chức năng khớp háng của tất cả bênh nhân đêu ở mức độ kém. Trên phim chup Xquang $90 \%$ bệnh nhân có hình ảnh tiêu xương đùi và/hoăc ổ cối. Kết luân: Lỏng khớp vô khuẩn là nguyên nhân hay gặp nhất khiến cho bệnh nhân phải thay lai khớp háng nhân taoo.

Tư khoá: thay lại khớp háng

\section{SUMMARY \\ CLINICAL AND RADIOGRAPHIC FEATURES OF PATIENTS WITH REVISION HIP ARTHROPLASTY}

Hip arthroplasty for the treatment of hip joint's diseases has been increasingly performed. However, some are not succesful and have revision. Aim: To evaluate clinical and radiographic features of patients

\section{${ }^{1}$ Bênh viên Viêt Đức \\ 2 Trường Đai hoc Y Hà Nôi}

Chịu trách nhiệm chính: Trân Mạnh Hùng

Email: drhung30@gmail.com

Ngày nhận bài: 17.5.2021

Ngày phản biên khoa hoc: 2.7.2021

Ngày duyệt bài: 19.7.2021

\section{Trần Mạnh Hùng ${ }^{1}$, Nguyễn Xuân Thuỳ ${ }^{2}$}

with revision hip arthroplasty. Patients and method: A cross-sectional descriptive study of 50 patients who were indicated for revision hip replacement due to aseptic hip prosthesis failure. Results: There were 41 patients underwent total hip replacement (82\%) and 9 patients underwent partial hip replacement $(18 \%)$ $(p<0,001)$. The mean time between the last surgery and the next revision surgery was $75,8 \pm 68,1$ months. The time between two hip replacements of cemented and non-cemented hip prosthesis was $121,0 \pm 68,6$ and $37,3 \pm 37,6$ months, respectively $(p<0,001)$. The reasons of failure after hip replacement were aseptic loosening $(72 \%)$, dislocation $(20 \%)$, peri-prosthesis fracture (4\%) and femoral stem fracture (4\%). Hip function of all patients was poor. Radiography showed that $90 \%$ of patients had femoral and/or acetabular bone loss. Conlusion: Aseptic loosening was the most common cause of revision hip replacement.

Keyword: revision hip replacement.

\section{I. ĐĂT VẤN ĐỀ}

Phẫu thuâtt thay khớp háng nhân tạo đã được thực hiện trển thế giới từ cuối thễ kỉ thứ 19 để điểu trị những trường hợp tổn thương khớp háng như gã்y cổ xương đùi do chấn thương, hoại tử chỏm xương đùi, thoái hoá khớp háng, viêm cột sống dính khớp, u xương.... Ước tính tỉ lệ thành công của phẫu thuật đạt trên $90 \%$, giúp hồ chức năng khớp háng và cải thiện chất lượng cuộc sống cho bệnh nhân. Cùng với sự già hoá dân số, số lượng phẫu thuật thay khớp háng nhân tạo ngày càng tăng. Tuy nhiên, khớp háng nhân tạo có tuổi thọ nhất định. Phẫu thuật thay lại khớp háng nhân tạo đã được nhắc đến trong y văn từ những năm 80 của thế kỉ trước [1]. Tỉ lệ thay lại khớp háng nhân tạo khoảng $1 \% /$ năm trong vòng 15 năm đầu [2].

Tại Việt Nam, phẫu thuật thay khớp háng nhân tạo lần đầu được thực hiện vào những năm 70 của thế kỉ trước, nhưng khoảng gần 20 năm nay mới thực sự được phát triển và áp dụng phố 
biến tại một số bệnh viện trong cả nước. Một số ca thay khớp háng nhân tạo lần đầu bị thất bại đã được phâuu thuật lại trong vài năm trở lại đây. Để tìm hiểu nguyền nhân dẫn đến thất bại sau khi thay khớp háng, chúng tôi thực hiện đề tài này với mục tiêu đánh giá đặc điểm lâm sàng và Xquang của bệnh nhân thay lại khớp háng nhân tạo.

\section{II. ĐỐI TƯợNG VÀ PHƯƠ'NG PHÁP NGHIÊN CỨU}

- Nghiên cứu mô tả trên 50 bệnh nhân có chỉ định phẫu thuật thay lại khớp háng nhân tạo tại Bệnh viện Việt Đức từ năm 2013 đến năm 2018.

Tiều chuấn lựa chọn: Bệnh nhân bị hỏng khớp háng nhân tạo khồng do nhiễm trùng có chỉ định thay lại khớp háng nhân tạo.

Tiêu chuẩn loại trừ: Bệnh nhân bị nhiễm trùng khớp háng hoặc từ chối tham gia vào nghiên cứu.

- Quy trình nghiên cứu: Bệnh nhân đáp ứng đây đủ tiêu chuẩn sẽ được khám ở thời điểm trước mổ để đánh giá triệu chứng cơ năng, chức năng khớp háng theo bảng chỉ số khớp háng của Harris, chụp Xquang khung chậu thẳng nghiêng để đánh giá trình trạng khớp háng nhân tạo và tình trạng xương quanh khớp. Tổn thương tiêu xương trên phim Xquang được đánh giá theo phân loại của Paprosky. Tổn thương gãy xương đùi quanh khớp được phân loại theo Vancouver.

\section{KẾT QUẢ NGHIÊN CứU}

3.1.Đặc điểm về tuổi và giới: Có 33 bệnh nhân nam (66\%) và 17 bệnh nhân nữ (34\%), sự khác biệt về giới có ý nghĩa thống kê $(p=0,033)$. Tuổi trung bình của nhóm nghiên cứu là $58,1 \pm 11,5$ tuổi (thấp nhất là 29 tuổi, cao nhất là 80 tuổi). Tuổi hay gặp nhất trong nghiên cứu là nhóm tuổi từ 50 đến 70 tuổi với 29 bệnh nhân chiếm tî lệ 58\%. Nhóm trên 70 tuổi có số lượng bệnh nhân ít nhất với 9 bệnh nhân chiếm tî̉ lệ $18 \%$. Có sự khác biệt rõ rệt về số lượng bệnh nhân giữa các nhóm tuổi $(p=0,001)$.

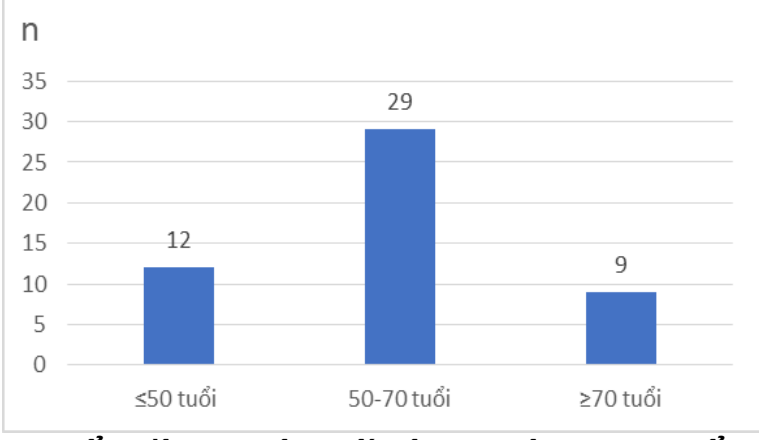

Biểu đồ 1. Phân bố bệnh nhân theo tuổi
3.2.Triệu chứng lâm sàng và cận lâm sàng. Tất cả bệnh nhân đều vào viện vì triệu chứng đau từ mức độ vừa trở lên. Đa số bệnh nhân đau khớp háng mức độ vừa (36 bệnh nhân chiếm tỉ lệ $72 \%$ ), 4 bệnh nhân đau trầm trọng (8\%), 10 bệnh nhân đau không thể chịu được (20\%). Thời gian từ lúc xuất hiện triệu chứng đau đến thời điểm khám trước mổ trung bình của 50 bệnh nhân trong nghiên cứu là $184,7 \pm 150,7$ ngày.

Trong số 50 bệnh nhân của nghiên cứu chỉ có 1 trường hợp đã thay khớp háng nhân tạo 2 lần, còn lại 49 bệnh nhân đều thay khớp háng 1 lần. Lý do thay khớp lần đầu được liệt kê trong bảng 3.1.

Bảng 3.1. Lý do thay khớp háng lân đâu

\begin{tabular}{|c|c|c|}
\hline Lý do thay khớp lần đầu & n & Tỉ lệ (\%) \\
\hline Tiêu chỏm xương đùi & 23 & 46,0 \\
\hline Gãy cố xương đưi & 20 & 40,0 \\
\hline Thoái hóa khớp & 4 & 8,0 \\
\hline $\begin{array}{c}\text { Tiêu cố xương đùi } \\
\text { sau mổ KHX }\end{array}$ & 2 & 4,0 \\
\hline Gãy mâ̂u chuyến & 1 & 2,0 \\
\hline Tống & 50 & 100 \\
\hline
\end{tabular}

Bảng 3.2. Loại khớp háng nhân tạo đã thay

\begin{tabular}{|c|c|c|c|c|}
\hline $\begin{array}{c}\text { Loaai } \\
\text { khớp }\end{array}$ & $\begin{array}{c}\text { Toàn } \\
\text { phần }\end{array}$ & $\begin{array}{c}\text { Bán } \\
\text { phân }\end{array}$ & Tổng & p \\
\hline $\begin{array}{c}\text { Có xi } \\
\text { măng }\end{array}$ & $20(40 \%)$ & $3(6 \%)$ & $23(48 \%)$ & \\
\cline { 1 - 3 } $\begin{array}{c}\text { Không xi } \\
\text { măng }\end{array}$ & $21(42 \%)$ & $6(12 \%)$ & $27(54 \%)$ & \multirow{2}{*}{0,672} \\
\cline { 1 - 4 } Tồng & $41(82 \%)$ & $9(18 \%)$ & $50(100 \%)$ & \\
\cline { 1 - 3 } p & \multicolumn{3}{|c|}{$<0,001$} \\
\hline
\end{tabular}

Có 41 bệnh nhân đã thay khớp háng toàn phần $(82 \%)$ và 9 bệnh nhân đã thay khớp háng bán phần $(18 \%)$, sự khác biệt có ý nghĩa thống kê với $p<0,001$. Tỉ lệ khớp có xi măng và không xi măng lần lượt là $48 \%$ và $54 \%$, tương đương nhau với $p=0,672$. Thời gian trung bình giữa hai lần thay khớp là 75,8 \pm 68,1 tháng (ngắn nhất là 19 ngày, dài nhất là 21 năm). Thời gian giữa hai lần thay khớp của nhóm khớp có xi măng và không xi măng lần lượt là $121,0 \pm 68,6$ và 37,3 $\pm 37,6$ tháng $(p<0,001)$.

Bảng 3.3. Các tổn thương xương và khớp háng nhân tạo trên phim Xquang

\begin{tabular}{|c|c|c|}
\hline Tổn thương & $\mathbf{n}$ & Tỉ lệ (\%) \\
\hline Ngắn chân & 45 & 90,0 \\
\hline Tiêu xương đùi & 34 & 68,0 \\
\hline Tiêu xương ổ cối & 30 & 60,0 \\
\hline Lún chuôi & 22 & 44,0 \\
\hline Trật khớp & 10 & 20,0 \\
\hline Gãy xương quanh khớp & 3 & 6,0 \\
\hline Gãy chuôi khớp & 2 & 4,0 \\
\hline
\end{tabular}


Phần lớn các bệnh nhân có dấu hiệu ngắn chân hoặc tiêu xương quanh khớp. Có đến $90 \%$ số bệnh nhân bị ngắn chân sau mổ thay khớp háng. Độ ngắn chân trung bình là $2,1 \pm 1,4 \mathrm{~cm}$ $(n=50)$. 10 bệnh nhân trật khớp gồm 2 bệnh nhân trật khớp tái diễn và 8 bệnh nhân trật khớp lần đầu nhưng không nắn chỉnh được. 3 bệnh nhân gãy xương quanh khớp gồm 2 bệnh nhân gãy xương đùi độ B3 (theo phân loại Vancouver) và 1 bệnh nhân bị vỡ thành ổ cối kèm trật khớp háng do chấn thương.

Về tổn thương tiêu xương đùi theo phân loai của Paprosky: độ I là 14\%, độ II là 34\%, độ IIIA là $16 \%$, độ IIIB là $4 \%$. Tốn thương tiêu xương ổ cối độ I là $10 \%$, độ IIA là $12 \%$, độ IIB hay gặp nhất là $32 \%$, độ IIC là $6 \%$. Có 5 bệnh nhẩn (10\%) không có tổn thương tiêu xương trên phim chụp Xquang.

3.3.Chỉ định thay lại khớp háng nhân tạo. Phẫu thuật thay lại khớp háng nhân tạo được chỉ định nhiều nhất cho nhóm bệnh nhân bị lỏng khớp đơn thuần không kèm theo tổn thương khác $(72 \%)$. Với những bệnh nhân vừa bị lỏng khớp vừa bị trật khớp hoặc gãy xương, gãy chuôi, chúng tôi lựa chọn trật khớp, gãy xương hoặc gãy chuôi là chỉ định chính của phẫu thuật thay lại khớp háng. Các chỉ định được thể hiện trong bảng 3.4.

Bảng 3.4. Chi dịnh thay lại khớp háng nhân tạo

\begin{tabular}{|c|c|c|c|c|}
\hline \multirow{2}{*}{\multicolumn{2}{|c|}{$\begin{array}{l}\text { Chỉ định thay lại } \\
\text { khớp }\end{array}$}} & \multicolumn{2}{|c|}{$\begin{array}{l}\text { Thời gian giữa } 2 \\
\text { lân thay khớp }\end{array}$} & \multirow{3}{*}{$\begin{array}{c}\text { Tổng } \\
36\end{array}$} \\
\hline & & \multirow{2}{*}{$\frac{\leq 5 \text { năm }}{18}$} & \multirow{2}{*}{$\frac{>5 \text { năm }}{18}$} & \\
\hline & $\mathrm{n}$ & & & \\
\hline Long kho & $\%$ & $62,1 \%$ & $85,7 \%$ & $72,0 \%$ \\
\hline \multirow{2}{*}{ Trật khớp } & $\mathrm{n}$ & 10 & 0 & 10 \\
\hline & $\%$ & $34,5 \%$ & $0 \%$ & $20,0 \%$ \\
\hline \multirow{4}{*}{$\begin{array}{l}\text { Gãy xương } \\
\text { quanh chuôi } \\
\text { Gãy chuôi } \\
\text { khớp }\end{array}$} & $\mathrm{n}$ & 1 & 1 & 2 \\
\hline & $\%$ & $3,4 \%$ & $4,8 \%$ & $4,0 \%$ \\
\hline & $\mathrm{n}$ & 0 & 2 & 2 \\
\hline & $\%$ & $0 \%$ & $9,5 \%$ & $4,0 \%$ \\
\hline \multirow{2}{*}{ Tổng } & $\mathrm{n}$ & 29 & 21 & 50 \\
\hline & $\%$ & $100 \%$ & $100 \%$ & $100 \%$ \\
\hline
\end{tabular}

\section{BÀN LUÂN}

Sau khi thay khớp háng xuất hiện những thay đổi cấu trúc xương xung quanh khớp nhân tạo làm ảnh hưởng tới kết quả cũng như tuổi thọ khớp háng như hiện tượng lỏng chuôi, các ổ tiêu xương quanh ổ cối hay chuôi khớp háng, hiện tượng mòn khớp hay do sai sót về kỹ thuật như lỏng khớp, khớp tư thế không đúng dẫn tới trật khớp hay mỏi khớp, nhiễm trùng.... Mặt khác, mỗi loại khớp háng có một tuổi thọ nhất định nên khớp háng nhân tạo không tồn tại vĩnh viễn. Thời gian giữa hai lần thay khớp của các bệnh nhân trong nghiên cứu của chúng tôi là $75,8 \pm$ 68,1 tháng (ngắn nhất là 19 ngày, dài nhất là 21 năm). Theo Malchau và cộng sự, khoảng 9095\% bệnh nhân thay khớp háng duy trì chức năng khớp ổn định trong vòng 10 năm đầu, $85 \%$ khớp háng nhân tạo còn giữ được hoạt động ở thời điểm 20 năm [3]. Tại Việt Nam chưa có hệ thống theo dõi các bệnh nhân đã thay khớp háng nên tỉ lệ bệnh nhân phải thay lại khớp háng chưa được thống kê. Trên thế giới, ước tính tỉ lệ thay khớp háng trong vòng 15 năm đầu tiên khoảng 1\% [2]. Tại Anh, có khoảng 5-6\% bệnh nhân phải thay lại khớp háng nhân tạo. Trong nghiên cứu của chúng tôi chỉ có 1 trường hợp đã thay khớp háng 2 lần với tiền sử bệnh ban đầu là thoái hoá khớp háng. Trong y văn đã có một số nghiên cứu về phẫu thuật thay khớp háng từ 3 lần trở lên. Với sự phát triển về số lượng khớp háng nhân tạo được thay hàng năm và tuổi thọ nhất định của khớp háng, trong tương lai số bệnh nhân phải thay lại khớp háng nhiều lần tại Việt Nam có thể sẽ ngày càng tăng.

Đau là triệu chứng cơ năng phổ biến nhất của các bệnh nhân. Đối với nhóm lỏng khớp, triệu chứng đau thường xuất hiện âm ỉ, từ từ tăng dần, có hướng lan xuống đùi (nếu lỏng chuôi khớp) hoặc lan lên bẹn (nếu lỏng ổ cối), ngược lại với nhóm trật khớp và gãy xương, gãy chuôi khớp là đau xuất hiện đột ngột. Thời gian xuất hiện triệu chứng đau trong nghiên cứu của chúng tôi là $184,7 \pm 150,7$ ngày. Đau thường kéo dài và bệnh nhân đi khám muộn do đặc điểm bệnh nhẩn nước ta có điều kiện kinh tế còn khó khăn, phẫu thuật thay khớp háng có chi phí cao nên bệnh nhân thường chịu đau kéo dài đến khi ảnh hưởng nhiều đến cuộc sống và sinh hoạt hàng ngày mới đi khám.

Chẩn đoán hình ảnh là xét nghiệm quan trọng đối với những bệnh nhân thay khớp háng. Trong các loại phương tiện chẩn đoán hình ảnh, chụp phim Xquang khung chậu thẳng nghiêng là xét nghiệm đầu tay khi bệnh nhân xuất hiện triệu chứng đau sau mổ. Đây là xét nghiệm đơnn giản, rẻ tiền, dễ thực hiện, giúp mang lại nhiều thông tin về tình trạng khớp háng nhân tạo và tình trạng xương quanh khớp như dấu hiệu lỏng khớp và tiêu xương quanh khớp, trật khớp, can xương lạc chỗ, gãy xương quanh khớp, mòn khớp [4]. Ngoài nhóm lỏng khớp, hình ảnh phim Xquang của những bệnh nhân vào viện vì nguyên nhân khác đều thẩy có dấu hiệu tiêu xương mức đô khác nhau. Chỉ có 5 bệnh nhân (10\%) không có 
hình ảnh tiêu xương quanh khớp, gồm 4 bệnh nhân bị trật khớp sớm sau mổ (từ 1 ngày đến 6 tháng) và 1 bệnh nhân gãy xương đùi sau mổ 1 năm. Mức độ tiêu xương đùi và xương ổ cối hay gặp nhất trong nghiên cứu này là độ II (34\%) độ IIB (32\%), Dấu hiệu tiêu xương nhiều hay ít là một trong những cơ sở để giúp phẫu thuật viên đưa ra quyết định thay lại toàn bộ hay một phần khớp háng nhân tạo.

Dựa vào phim Xquang khung chậu, chúng tôi xác định loại khớp háng nhân tạo đã thay lần đầu là toàn phần hay bán phần, có hay không có xi măng. Kết quả cho thấy phần lớn bệnh nhân được thay khớp toàn phần (82\%), chỉ có $18 \%$ thay khớp bán phần. Tất cả các chuôi khớp thay lần đầu đều sử dụng là loại chuôi ngắn, 1 bệnh nhân thay lại lần 2 có sử dụng loại chuôi dài. Việc sử dụng xi măng vẫn là chủ để được tranh luận nhiều nhất trong phẫu thuật thay khớp háng, và được coi là một yếu tố ảnh hưởng đến kết quả phẫu thuật. Khớp háng không xi măng được cho là có thể khắc phục được hiện tượng lỏng khớp thường thấy trong hệ thống khớp có xi măng. Tuy nhiên cho đến nay, tuổi thọ của khớp háng có xi măng vẫn lâu hơn khớp không xi măng. Kết quả so sánh giữa các quốc gia có hệ thống theo dõi những bệnh nhân thay khớp háng cho thấy tỉ lệ sử dụng khớp háng không xi măng càng cao thì tỉ lệ thất bại sau thay khớp càng cao [3]. Điều này có thể lí giải vì sao tỉ lệ bệnh nhân thay khớp không xi măng trong nghiên cứu của chúng tôi cao hơn nhiều so với số bệnh nhân thay khớp có xi măng. Kết quả nghiên cứu cũng cho thấy thời gian giữa hai lần thay khớp của nhóm khớp có xi măng dài hơn khớp không xi măng. Tuổi thọ của khớp không xi măng trung bình là $37,3 \pm 37,6$ tháng, khớp có xi măng là $121,0 \pm 68,6$ tháng $(p<0,001)$. Như vậy nhóm khớp có xi măng thì thời gian phải thay lại khớp muộn hơn nhóm khớp không xi măng.

Về nguyên nhân thất bại không do nhiễm trùng sau thay khớp háng, lỏng khớp chiếm tỉ lệ cao nhất là $72 \%$. Nguyên nhân hay gặp thứ hai là trật khớp (20\%). Một số nguyên nhân ít gặp hơn là gãy xương quanh chuôi $(4 \%)$ và gãy chuôi khớp $(4 \%)$. Kết quả này cũng phù hợp với nghiên cứu của nhiều tác giả khác. Lỏng khớp là nguyên nhân thất bại hay gặp nhất sau phẫu thuật thay khớp háng nhân tạo. Quá trình tiêu xương quanh quanh khớp nhân tạo vô khuẩn dẫn tới lỏng khớp có thể gây ra bởi các mảnh võ nhỏ từ các thành phần khớp háng nhân tạo. Nguyên lý của hiện tượng này là do quá trình viêm và tiêu xương. Các mảnh võ̃ chủ yếu tạo ra từ bề mặt khớp vẫn là nhân tố chính hạn chế sự tồn tại của khớp háng nhân tạo. Sự xuất hiện và duy trì phản ứng viêm mạn tính được khởi sướng bởi các mảnh võ tại giao diện giữa khớp nhân tạo và xương, kích thích hoạt động của hàng loạt tế bào. Những tế bào bao gồm: đại thực bào, nguyên bào sợi, các tế bào khổng lî̀, bạch cầu trung tính, bạch cầu lympho và quan trọng nhất là hủy cốt bào. Tiến triển của sự phá hủy các mô xung quanh khớp nhân tạo là một thách thức lớn bởi các biểu hiện không rõ ràng mà âm thầm dẫn cho tới khi hỏng khớp thực sự. Khi tổ chức xương quanh khớp nhân tạo bị tiêu đi, xuất hiện các ổ viêm và tiêu xương bao quanh khớp háng nhân tạo làm cho tình trạng lỏng khớp tăng lên [5].

Trong nghiên cứu của Dobzyniak, tỉ lệ thay lại khớp háng trong vòng 5 năm đâuu là $39 \%$, nguyên nhân hay gặp nhất là trật khớp (33\%) và lỏng khớp không do nhiễm trùng (30\%) [6]. Đây cũng là 2 nguyên nhân hay gặp trong số những bệnh nhân phải thay lại khớp trong 5 năm đâuu trong nghiên cứu của chúng tôi. Tỉ lệ lỏng khớp tăng dần lên theo thời gian và là nguyên nhân gây thất bại muộn. Trong khi trật khớp thường xảy ra sớm và là nguyên nhân khiến cho bệnh nhân phải thay lại khớp sớm hơn. Trật khớp xảy ra sớm sau phẫu thuật có thể liên quan đến kĩ thuật mổ. Do kỹ thuật không đặt đúng vị trí của ổ cối (nghiêng 45 độ và ra trước 20-25 độ), hậu quả bệnh nhân có thể trật khớp ra trước hoặc ra sau; có thể do bất tương xứng của khớp háng nhân tạo làm khớp bị lỏng, do bệnh nhân vận động sai tư thế, do mòn lớp lót ổ cối dẫn tới sự bất tương xứng khớp.

\section{KẾT LUÂ̂N}

Có nhiều nguyên nhân gây thất bại sau phẫu thuật thay khớp háng trong đó lỏng khớp không do nhiễm trùng là nguyên nhân hay gặp nhất. Tỉ lệ khớp không xi măng phải thay lại cao hơn so với khớp có xi măng. Tỉ lệ bệnh nhân bị lỏng khớp cần thay lại khớp háng nhân tạo tăng lên theo thời gian do những biến đổi sinh học xung quanh khớp nhân tạo. Bệnh nhân cần được theo dõi định kì trên lâm sàng và phim Xquang để phát hiện các tổn thương và đưa ra chỉ định thay lại khớp háng phù hợp.

\section{TÀI LIÊU THAM KHẢO}

1. Pellicci, P.M., et al., Long-term results of revision total hip replacement. A follow-up report. J Bone Joint Surg Am, 1985. 67(4): p. 513-6.

2. Crawford, R.W. and D.W. Murray, Total hip replacement: indications for surgery and risk factors for failure. Annals of the Rheumatic Diseases, 1997. 56(8): p. 455. 
3. Malchau, H. and P. Herberts, Prognosis of total hip replacement. Int J Risk Saf Med, 1996. 8(1): p. 27-45.

4. Mushtaq, N., et al., Radiological Imaging Evaluation of the Failing Total Hip Replacement. Frontiers in surgery, 2019. 6: p. 35-35.

5. Abu-Amer, Y., I. Darwech, and J.C. Clohisy, Aseptic loosening of total joint replacements: mechanisms underlying osteolysis and potential therapies. Arthritis research \& therapy, 2007. 9 Suppl 1(Suppl 1): p. S6-S6.

6. Dobzyniak, M., T.K. Fehring, and S. Odum, Early failure in total hip arthroplasty. Clin Orthop Relat Res, 2006. 447: p. 76-8.

\section{KHẢO SÁT TỈ LÊ TRÂM CẢM VÀ CÁC YẾU TỐ LIÊN QUAN TRÊN PHU NỮ MANG THAI Ở 3 THÁNG CUỐI THAI KỲ TẠI BÊ̂NH VIÊ̂N NGUYỄN TRI PHƯƠNG}

\section{TÓM TẮT}

Đă̆t vấn đề: Phụ nữ mang thai bi trầm cảm thường có diễn tiến năng hơn phụ nữ không mang thai vì sự xuất hiện trạng thái lo âu rõ rệt, thậm chí có cơn hoảng loan, có thể xuất hiên ý đinh tự hủy hoai bản thân, tự tử. Nghiên cứu được thực hiện nhằm xác đinh tỉ lê trầm cảm và các yếu tố liên quan trầm cảm ở phu nữ mang thai 3 tháng cuối tại Bệnh viện Nguyển Tri Phương bằng việc sữ dung thang đo trầm cảm EPDS. Phương pháp nghiên cứu: Nghiên cứu cắt ngang đánh giá nguy cơ trâm cảm khảo sát qua 310 phụ nữ mang thai từ $\geq 28$ tuân đến khám thai tại Bênh viên Nguyễn Tri Phương trong giai đoan 20/01/2021 - 20/04/2021. Thang đo EPDS phiên bản tiếng Viêt sử dung sàng loc nguy cơ trầm cảm ở tất cả phư nữ mang thai 3 tháng cuối, với điểm cắt $\geq 13$ điểm được xem là có nguy cơ trầm cảm trước sinh. Các thai phụ có nguy cơ cao được theo dõi bởi chuyên khoa tâm thần và bác sĩ sản khoa cho đến khi sinh và đánh giá các biến cố khi sinh. Kết quả: Tỷ lê thai phụ mang thai giai đoạn $\geq 28$ tuần có nguy cớ trầm cảm trước sinh (EPDS $\geq 13$ ) chiếm 28,7\% [KTC95\%: 23,2 - 33,5]. Các yếu tố nguy cơ liên quan đến sự xuất hiên trầm cảm trước sinh bao gồm: thai phụ thuôc nhóm tuổi >25 tuổi tăng nguy cơ TCTS gấp 3,9 lẩn (KTC 95\%: 1,3 - 12,5, p=0,018), thai phu không tôn giáo và có tình trạng kinh tế khó khăn (tăng TCTS lần lướt là 7,01 lần [KTC 95\%: $1,1-8,1, p=0,036$ ] và 3,03 lần [KTC 95\%: 1,1 - 8,1, $p=0,026$ ]. Trạng thái tinh thần không ổn định (thai phụ có lo lắng trong quá trình mang thai), các xung đột trong mối quan hệ (bất hoà với gia đình chồng và thiếu người tâm sứ) làm tăng nguy cơ TCTS lần lượt 8,5 lần [KTC 95\%: 3,918,3; $p=0,000$ ] 6,3 lần [KTC 95\%: 1,6-25,3; $p=0,009$ ] và gấp 2,7 lần [KTC 95\%: 1,2-6,1; $p=0,019$ ]. Thai phụ không nhân đước tư vấn từ cán bô $Y$ tế tăng nguy cơ TCTS gấp 2,5 lần [KTC 95\%:1,1-5,4; $p=0,019]$. Kết

\footnotetext{
${ }^{1}$ Bệnh viện Nguyễn Tri Phương

2Trường đai hoc Y Dướ TP.HCM

Chiu trách nhiệm chính: Tô Mai Xuân Hồng

Email: tomaixuanhong@ump.edu.vn

Ngày nhận bài: 13.5 .2021

Ngày phản biện khoa học: 30.6.2021

Ngày duyệt bài: 12.7.2021
}

\section{Trần Thị Trúc Phương1, Tô Mai Xuân Hồng²}

luận: Trâm cảm trước sinh cần được sàng lọc và điều tri kip thời để hạ chế các kết cực thai kỳ xấu cho thai phụ và thai nhi. Sử dụng thang đo EPDS với điểm cắt $\geq 13$ là một công cụ hữu hiệu trong tầm soát nguy cơ trâm cảm trước sinh.

Tư khóa: phụ nữ mang thai, trâm cảm, EPDS

\section{SUMMARY}

\section{PRENATAL DEPRESSION PREVALENCE AND RISK FACTORS OF PREGNANT WOMEN AT THE THIRD TRIMESTER IN NGUYEN TRI PHUONG HOSPITAL}

Background: Pregnant women who are suffered from depression often have a tendence getting more severe anxiety and probably becoming panic attacks, self-destructive, and suicidal thoughts. The study is aimed to evaluate the prevalence of prenatal depression and risks factors of pregnant women in the third trimester at Nguyen Tri Phuong hospital by using EPDS scale. Research: A cross-sectional study was carried out in 310 pregnant women from 28 weeks, who came to antenatal care at Nguyen Tri Phuong hospital in the period 20/01/2021 - April 20, 2021. The EPDS scale in Vietnamese version was applied to classify the pregnant women at high-risk or low-risk at prenatal depression. A cut-off point at 13 points is considered at high-risk at prenatal depression. All high-risk pregnancies were followed up by both obstetricians and psychiatrist until the delivery in order to evaluate maternal and fetal outcomes, Results: The prevalence of prenatal depression (EPDS $>=13$ ) of pregnant women at third trimester is $28,7 \%$ [CI 95\%: $23,2-33,5]$. There are some risk factors of prenatal depression: the age group at 25 years or older, pregnant women with non-religion and low economics have higher possibility of prenatal depression from 3,9 times $[95 \% \mathrm{CI}$ : $1,3-12,5$; $p=0,018]$ to 7,01 times [ $95 \%$ CI:1,1-8,1; $p=0,036]$, and 3,03 times [95\% CI: $1,1-8,1 ; p=0,026]$. Pregnant women with anxiety, social and family conflict, and lacking of buddies chat are also risk factors of prenatal depression with relative risk from 8,5 [95\% CI: 3,9$18,3 ; p=0,000]$ to 6.3 times [95\% CI: $1,6-25,3$; $p=0,009]$ and 2,7 times [95\% CI: $1,2-6,1 ; p=0,019]$. Pregnant women who do not have a consult from health workers increase the risk of prenatal depression 